\title{
DATA LOAD MANIFESTATION IN PROCESS CHAINS IN SAP BUSINESS WARE HOUSE
}

\author{
M. Victoria Hebseeba ${ }^{1}$, Dr. T. Bhasakara Reddy ${ }^{2}$, Prof. B. Lakshma Reddy ${ }^{3}$ and \\ Dr. T. Venkateswarulu ${ }^{4}$ \\ ${ }^{1}$ Department of Computer Science, Rayalaseema University, Andhra Pradesh \\ victoria.hebseeba@gmail.com \\ ${ }^{2}$ Department of Computer Science, S.K University, Andhra Pradesh \\ bhaskarreddy_sku@yahoo.co.in \\ ${ }^{3}$ Director, Garden City College, Bangalore, Karnataka \\ mail2reddy99@gmail.com \\ ${ }^{4}$ Department of Computer Science, Gate College, Tirupathi \\ venkat_tammineni@yahoo.com
}

\begin{abstract}
This paper describes a unique technique to display the run times of the process chains, number of records transferred to each target, frequency and other details. We do not have any ready option provided by SAP to display all these details for multiple process chains in one place as displayed here. This customised report developed using business content info cubes helps us to analyse the run times for the loads in process chains and derive conclusions on the performance, data, frequency and other details. Report allows us to choose the result as per our requirement by providing the selection criteria in the selection screen.
\end{abstract}

\section{KEYWORDS}

Process Type, Variant, Business Warehouse, ETL

\section{DATA EXTRaCtion, Transformation AND LOADING}

A process chain is a mechanism that controls extraction, transformation, and loading (ETL) activities execution at a scheduled time in a defined Sequence. Since in many support project environments in IT industry multiple process chains are run you come across some issues with the system executing them at appropriate times. A process chain is a BW objects which has scheduled sequence of processes linked together and are executed in a specified order.

Process chain waits in the back ground for an event. Some of these processes trigger a separate event that can start other processes in turn. In an operating system there are a multitude of processes in addition to the loading process that occur regularly [1] [2]. Process chain is a mechanism that controls extraction, transformation, and loading (ETL) activities execution at a scheduled time in a defined manner. Process chains are used to automate the complex structures with the help of the controlled processing, visualize the schedule by using network applications and centrally control and monitor the processes [3] [4].

Openness is applied to the theory behind process chains, in that both user-defined programs and processes can be implemented. In addition, you can include process chains in other process chains, so-called Meta chains. In doing so you have the option of integrating process chains from the BW system, in which the Meta chain is found, or from other BW systems [5] [6]. In this context, local or remote process chains are concerned. Processes are scheduled before your run and can be monitored with the standard batch monitor. You start subsequent processes by 
using background events. Short dumps and terminations are recognized and handled respectively [7] [9].

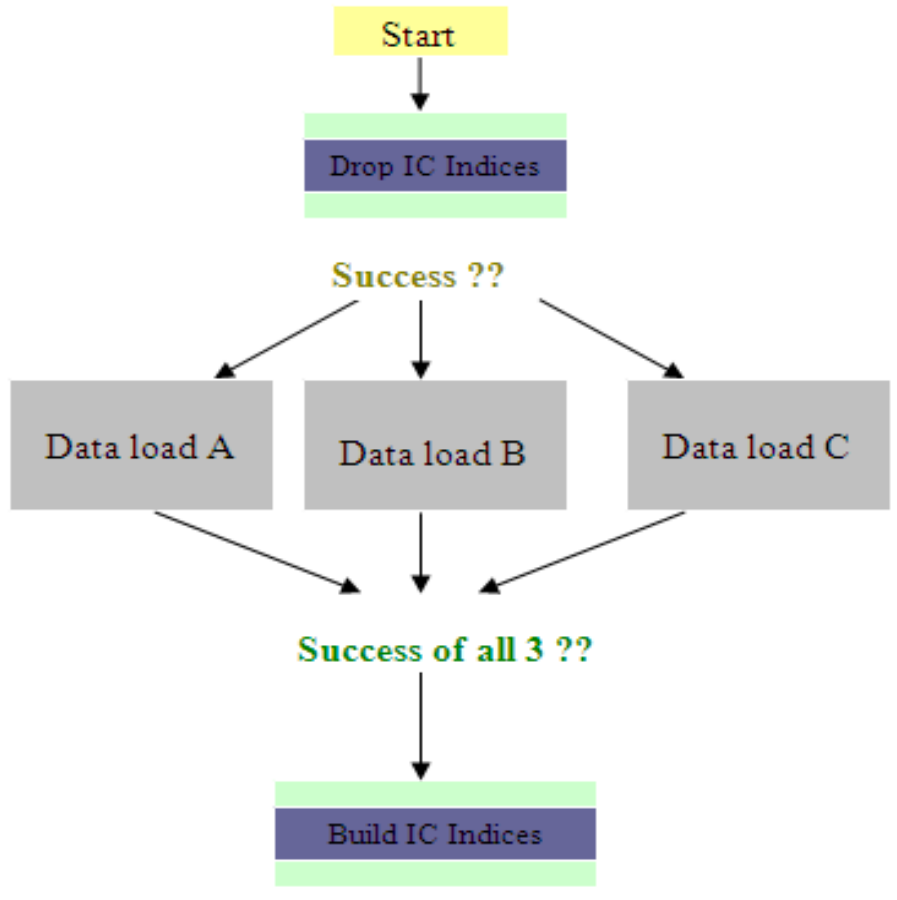

Figure 1: Building a process flow: Data loading from Info packages in parallel to 1 Info cube.

\section{DATA LOAD MANIFESTATION}

One of the BW's strongest selling points is its business objects developed by SAP based on predefined business roles and their tasks. For instance a sales general manager needs reports to get business information and conduct analysis. SAP provides set of BW objects developed called as business content objects to support operation level application programming tasks. It contains roles, work books, queries, info cubes, key figures, characteristics, update rules, info sources, and extractors for SAP R/3.

A multi provider C_YTCT_M is created by the union of basic cubes. The multi provider created does not contain any data by itself; rather the data reside in the basic cubes 0TCT_C21, 0TCT_C22, and 0TCT_C23.

To a user multi provider resembles a basic cube. The below figure displays the multi provider created by selecting the business content cubes to derive the DTP, info package and process details included in various process chains in the system. 


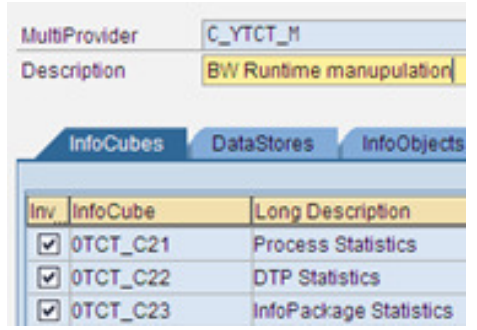

Figure 2: Multi provider BW Run time manipulation

The data from transactional data from data sources is extracted to the destination info cubes after the data pass through the info sources from various info cubes which pick the data from Info sources.

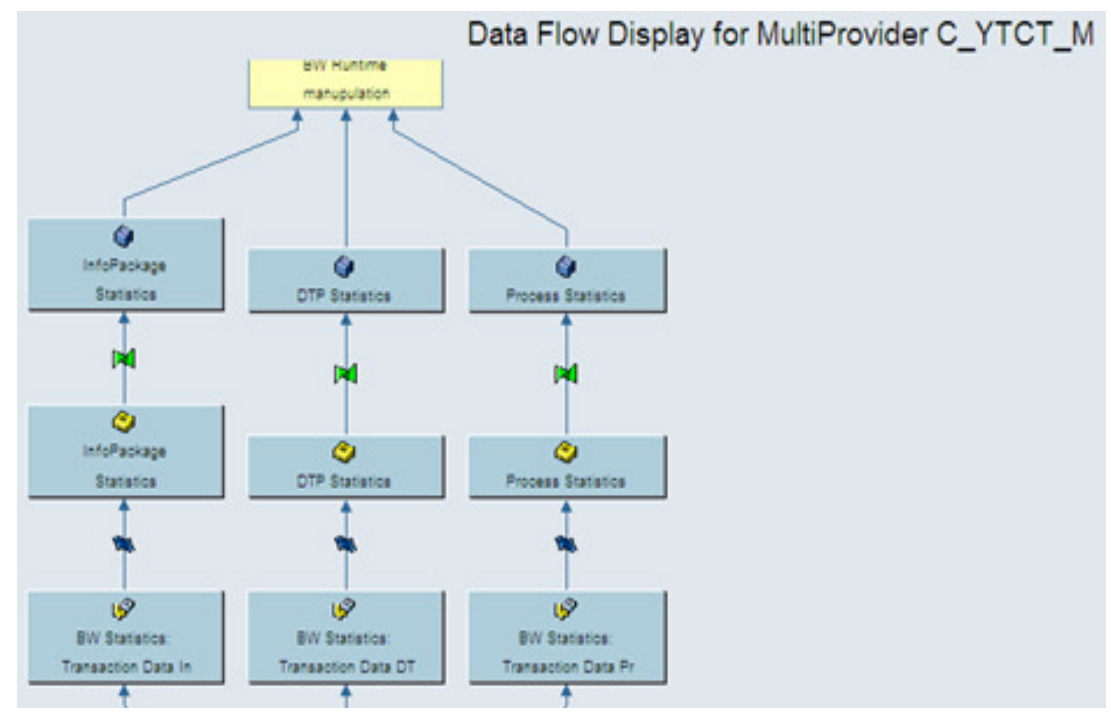

Figure 3: Data flow for Multi provider C_YTCT_M

\subsection{Fields Display}

On the multi provider a new report is created in the system to capture the no. of iteration of PCs, records from IP and DTP etc details. Chosen duration, frequency, number of records, data transfer process records, calendar day in key figures to be displayed in columns in the output of the report. Arranged rows to display the system details and then process chain id, process chain type, process variant. Selected UTC time stamp is free characteristics. Time stamp being a free characteristic allows further drill down. This helps in reducing the input/ out put volume for the initial query result, there by improving the query performance. 


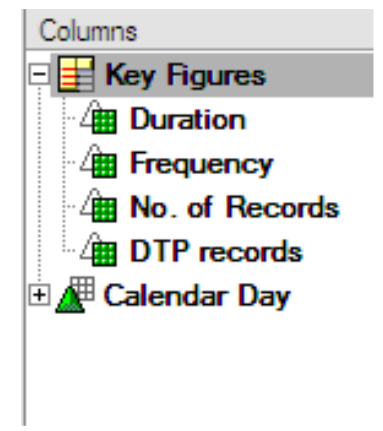

Figure 4: Columns

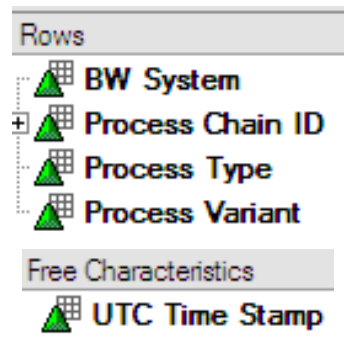

Figure 4: Rows and Free Characteristics

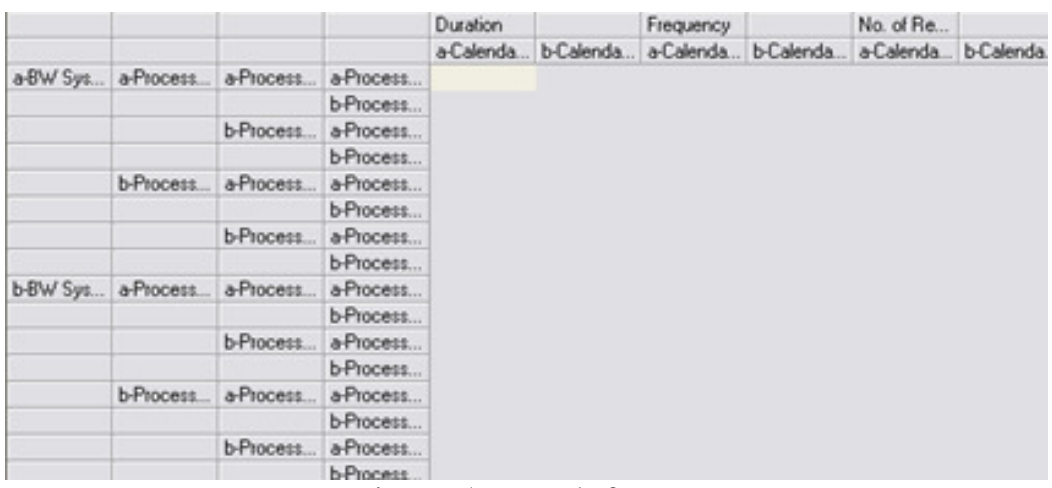

Figure 5: Result format

\subsection{Test Results}

- Performed several lab tests. Executed the process chains. Compared the result displayed with that of the info packages inside the process chain.

- The status displayed was exactly matching in both the scenarios.

- Enter the date range. For example: 1/11/2011 to 30/11/2011 and give process chain technical name if required in the variables screen.

\section{Conclusions}

Process Chains are the new generation of job scheduling and monitoring tools for tasks such as data loads, reporting agent jobs, or index rebuilds.

The proposed approach is best suited for to be executed daily or when ever required to get the complete data load details. This approach very helpful to the ETL team in Business Ware house 
support project environments to view and analyze the data load status and system performance

for multiple process chains in the system collated in one sheet. This approach has demonstrated good results in our preliminary experiments.

\section{REFERENCES}

[1] Olaf Klostermann and Milco Osterholm, (2006) " SAP Net weaver BW Administration and Monitoring", 1st ed., Galileo Press, Germany.

[2] Andrew J. Ross, (2009)" SAP Net weaver BI Accelerator", 1st ed., Galileo Press, Boston (MA), USA.

[3] Christian Merwald, Sabine Morlock, (2009) " Data Ware Housing with SAP BW7, BI in SAP Net Weaver 2004s" 1st ed., Rocky Nook Inc.,

[4] Biao Fu and Henry Fu. (2002) "SAP BW a step by step guide".

[5] Arshad Khan,(2005) "SAP and BW Data Warehousing. How to plan and implement".

[6] Frank K. Wolf and Stefan Yamada, "Data Modeling in SAP Net weaver BW", $1^{\text {st }}$ ed., Galileo Press, Boston,(MA)

[7] Kevin McDonald, Andreas Wilmsmeier, David C. Dixon and W.H Inmon,(2002) "Mastering the SAP Business Information Ware house" Wiley Publishing Inc, USA .

[8] Elizabeth Vitt and Michael Luckevich and StaciaMisner, "Making better Business Intelligence Decisions faster", Microsoft Press, USA

[9] Daniel Knapp, "Practical Data modeling with SAP Net Weaver BW", Galileo Press, Boston (MA), USA

[10] http://airccse.org/journal/ijngn/papers/3111ijngn04.pdf

[11] http://www.ijmo.org/papers/13-P30001.pdf

[12] http://airccse.org/journal/acij/papers/1111acij08.pdf 